\title{
THE CORRELATION BETWEEN SEXUAL DYSFUNCTION AND MARITAL RELATIONSHIP AMONG WOMEN WITH GYNAECOLOGICAL PROBLEMS
}

\author{
Nunung Nurhayani, Utami Nur Ulsiyah, Suci Noor, Dewi Marfuah, Linlin Lindayani*
}

Sekolah Tinggi Ilmu Kesehatan PPNI Jawa Barat, Indonesia

\section{Article Information}

Received: 13 November 2019

Revised: 9 March 2020

Accepted: 22 July 2021

\section{*Corresponding Author}

Linlin Lindayani

linlinlindayani@gmail.com

\section{DOI}

10.20884/1.jks.2021.16.1.1240

\begin{abstract}
Women with gynaecological problems are at high risk of having sexual dysfunction because the problems could affect the marital relationship and sexual satisfaction. The purpose of this study is to determine the relationship between sexual dysfunction and marital relationships in women with gynaecological problems. This study was conducted using a cross-sectional study. The samples were women with gynaecological problems, aged above 18 years old, married, and able to communicate well. Patients with mental disorders were excluded from this study. Convenience sampling was used to select participants. The marital relationship was measured using a validated instrument, namely, Revised Dyadic Adjustment Scale (RDAS) and the Female Sexual Function Index (FSFI). A total of 82 women with gynaecological problems joined our study. The majority of the respondents experienced sexual dysfunction (90.2\%) and more than half of the respondents (52.4\%) experienced distress in marital relationships. There was a relationship between sexual dysfunction and marital relationship among women with gynaecological problems ( $p$ value $<0.005$ ) and the coefficient correlation was 0.326 . Sexual dysfunction may affect marital relationships in women with gynaecological problems. Healthcare professionals need to provide appropriate intervention to women with gynaecological problems as well as facilitate them to express their sexual activity.
\end{abstract}

Keywords: Gynaecological problems; marital relationships; sexual dysfunction

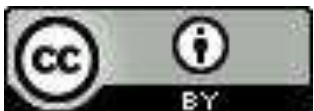

ISSN : 1907-6637

e-ISSN : 2579-9320

\section{INTRODUCTION}

Gynecological diseases involve the women's reproductive tract and include benign and malignant tumors, diseases associated with pregnancy, infection, and endocrine disorders (e.g., myoma, endometriosis, dysmenorrhea, cyst, infertility, hypermenorrhea, ovarium cancer, cervical cancer, and endometrium cancer) (Mok et al., 2020), which malignant tumors are the leading cause of death among them (Hicks-Courant et al., 2018). Gynecological problems are influenced by menstrual hygiene, sex hygiene, socioeconomic status, cultural habits, and women's education (Beaulah, 2018). About $92 \%$ of women worldwide are affected by gynecological diseases (Puechl et al., 2019). A study conducted in Aceh, Indonesia, reported that benign tumors $(47.25 \%)$ were the most prevalent disease of gynecology problems in 2017 (Nora \& Khalishah, 2018). However, data on gynecological diseases for the total of Indonesia remind limited.
Gynecological problems can disrupt normal sexual function, which is a crucial aspect of women's health (Dawson et al., 2017). Women with gynecological problems are at high risk of sexual dysfunction, including diminished arousal, problems achieving orgasm, dyspareunia, and low desire (Dawson et al., 2017). The prevalence was noted to be between $40 \%$ and $50 \%$ (Nappi et al., 2016). A previous study found that up to $80 \%$ of women with endometrial cancer experienced sexual dysfunction after treatment (Damast et al., 2012). Sexual dysfunction is an important predictor of lower quality of life among women (Nappi et al., 2016). Previous studies conducted in young women with ovarian cancer reported decreased sexual function that caused depression, anxiety, and lack of confidence (Guntupalli et al., 2017). Another study found that women who had sexual problems experienced significant levels of pain, exhaustion, decreased desire, and anorgasmia (Liavaag et al., 2008). A comprehensive understanding of 
sexual function across the spectrum of gynecologic disorders was not addressed in the previous study.

Sexual intercourse is an important aspect of quality of life in cervical cancer patients, before, during, and after treatment. Compared with other gynecological cancers (endometrial, ovarian, and vaginal cancers), cervical cancer is a leading cause of sexual dysfunction and intimate partner problems (Vermeer et al., 2016). Treatment for cervical cancer can cause various side effects that can have an impact on decreased function, relationships, and sexual activity (Abbott-Anderson \& Kwekkeboom, 2012). These physical disorders can cause psychological disorders such as sexual desire disorder, loss of intimate relationship with a partner, lack of self-confidence, anxiety, and body image disorder (Brotto et al., 2008). The incidence of divorce of women who have cervical cancer is very high compared to the incidence of other cancers (Yuan et al., 2021). Sexual disorders caused by physical changes associated with cancer treatment resulted in a decrease in partner sexual activity (Shankar et al., 2017).

A marital relationship is a subjective assessment of a variety of experiences, including feelings and attitudes, that is influenced by intraindividual factors. Previous study explained the five components of marital relationships, which are overcoming conflict, joint decision making communication quality, sexual relations and intimacy, and relational values such as respect, trust, empathy, and understanding (Helms, 2013). There are three aspects in the interaction of marital relationships, including consensus, cohesion, and expression of affection ( Bryant \& Wickrama, 2005). The consensus includes financial, leisure activities outside the home, religious activities, joint decision making friendship between partners, relationships with in-laws, and career opportunities. Cohesion is related to the close emotional relationship of a married couple. Expressions of affection are sexual relationships and maintain the quality of long-term marriage.

Marital relationships could be impaired by problems in sexual function and linked to sexual satisfaction. Previous studies emphasized that sexual satisfaction was positively associated with overall relationship satisfaction (Ashdown et al., 2011). However, in women with gynecological problems who may have experienced sexual dysfunction, marital relationships could be impaired. For this reason, it is essential to determine the relationship between sexual dysfunction and marital relationships to help couples build and maintain a healthy relationship. However, there is a lack of information about the relationship between sexual dysfunction and marital relationships in women with gynecological problems. This study aims to identify the association between sexual dysfunction with marital relationships in women with gynecological problems.

\section{METHOD}

\section{Study design}

This study was conducted using cross-sectional design at one of the hospitals in Bandung from June to July 2019.

\section{Sample}

The population in this study were women with gynecological problems including benign and malignant tumors, diseases associated with pregnancy, infection, and endocrine disorders. The convenience sampling method was used to select the samples. The inclusion criteria were patients with gynecological problems, who are married, able to communicate well, and without mental disorders. The sample size was calculated using $G^{*}$ Power Software Version 3.1.9.2 using t-test: Correlation - point biserial model assuming $\alpha=0.05$, effect size 0.3 (Schäfer \& Schwarz, 2019), power level $=0.80$ and resulted in the minimum sample size that was 82 respondents.

\section{Instrument}

There were two instruments used in data collection on the Likert scale. The marital relationship was measured using the Revised Dyadic Adjustment Scale (RDAS) instrument developed by (Busby et al., 1995). RDAS is a questionnaire that assesses the seven dimensions of partner relationships in three overall categories of accession (decision making, values, and affection), satisfaction (satisfaction in a relationship related to stability and conflict), and cohesion (activities and discussion). In the current study, the Cronbach alpha coefficient was 0.90 .

Sexual dysfunction was assessed by the Female Sexual Function Index (FSFI) developed by (RC et al., 2000). The FSFI has 19 question items to assess the dimensions of sexual function in women with six domains, which are desire, arousal, lubrication, orgasm, satisfaction, and pain. In the current study, the Cronbach alpha coefficient was 0.82 .

\section{Data analysis}

A univariate and bivariate analysis was applied to determine the relationship between sexual dysfunction and marital relationships in women with gynecological problems. The chi-square test was applied in this study due to the data of independent and dependent variables were categorical data. All analysis was conducted using licensed SPSS software version 20 .

\section{Ethical consideration}

This study has been approved by ethical committee of Sekolah Tinggi IImu Keperawatan PPNI Jawa Barat (III/032/KEPK/STIKep/PPNI/JABAR/2019).

\section{RESULT}

A total of 82 women with gynecological problems joined this study. Table 1 shows that more than half of the respondents were in the age of more than 35 years old (64.6\%). The highest education level of respondents was high school $(36.6 \%)$ and only $17.1 \%$ of the respondents graduated with a bachelor's degree. Most respondents were unemployed $(86.6 \%)$ with a number of children more than two (40.2\%). The major gynecological problems reported were cyst (37.85), followed by myoma (23.2\%), and cervical cancer (12.2\%).

Table 1. Characteristics of respondents $(n=82)$

\begin{tabular}{lll}
\hline Characteristics & $\mathbf{n}$ & $\%$ \\
\hline Age (years old) & 2 & 2.4 \\
$<20$ & 27 & 32.9 \\
$20-35$ & 53 & 64.6 \\
$>35$ & & \\
\hline Education level & 18 & 22.0 \\
Elementary school & 20 & 24.4 \\
Junior high school & 30 & 36.6 \\
Senior high school & 14 & 17.1 \\
$\quad$ University level & & \\
\hline Working status & 71 & 86.6 \\
Unemployed & 8 & 9.8 \\
Private sector & 2 & 2.4 \\
Entrepreneur & 1 & 1.2 \\
Government employee & &
\end{tabular}




\begin{tabular}{lll}
\hline \hline & $\mathbf{n}$ & \\
\hline Characteristics & $\%$ \\
\hline $\begin{array}{l}\text { Prevalence of gynecological } \\
\text { problems }\end{array}$ & & \\
Myoma & 19 & 23.2 \\
Endometriosis & 8 & 9.8 \\
Dysmenorrhea & 3 & 3.7 \\
Cyst & 31 & 37.8 \\
Infertil & 1 & 1.2 \\
Hypermenorrhea & 3 & 3.7 \\
Ovarium cancer & 6 & 7.3 \\
Cervical cancer & 10 & 12.2 \\
Endometrium cancer & 1 & 1.2 \\
\hline
\end{tabular}

Almost all respondents (90.2\%) reported that they have sexual dysfunction and more than half of them have problems in marital relationships (52.4\%) (Table 2). Seventy nine point five percent of women who experienced sexual dysfunction reported that they have marital relationship distress.

Table 2. Marital relationships and sexual dysfunction in women with gynecological problems $(n=82)$.

\begin{tabular}{lcc}
\hline & $\mathbf{n}$ & $\%$ \\
\hline Marital relationships & & \\
$\quad$ Good & 39 & 47.6 \\
$\quad$ Distress & 43 & 52.4 \\
\hline Sexual dysfunction & & \\
No & 8 & 9.8 \\
Yes & 74 & 90.2 \\
\hline
\end{tabular}

Tabel 3. Relationship between sexual dysfunction and marital relationships in women with gynecological problems $(n=82)$

\begin{tabular}{llllc}
\hline Marital & \multicolumn{2}{c}{ Sexual dysfunction } & \multirow{2}{*}{$\chi^{2}$} & \multirow{2}{*}{$\boldsymbol{p}$ value } \\
\cline { 2 - 3 } relationship & No, $\mathbf{n}(\%)$ & Yes, $\mathbf{n}(\%)$ & & \\
\hline Good & $8(20.5)$ & $31(79.5)$ & 11.326 & 0.002 \\
Distress & $0(0.9)$ & $43(100)$ & & \\
\hline
\end{tabular}

There was a relationship between sexual dysfunction with marital relationship in women with gynecological problems, with the results of $p$ value being 0.002 and the coefficient correlation was 0.326 (Table 3 ). Women who experienced sexual dysfunction reported to have three times higher of getting distressed in their marital relationship.

\section{DISCUSSION}

Marriage satisfaction is a general assessment of the marital conditions that a person goes through. A marriage relationship is a state of mind to maintain a relationship that includes dependence and trust that someone will not leave the relationship that was built before (Handayani, 2016). Numerous factors may be connected with marital satisfaction, including increased educational attainment, improved physical and psychological health, increased socioeconomic standing, and positive relationships with family members. (Nogueira et al., 2019). Cultural factors have a large impact on the quality and satisfaction of marital relationships (Sorokowski et al., 2017). For example, in Western culture, people tent to be very very optimistic and no perception of sexual talk as a tabo comapre to Eastern culture (Zegeye et al, 2020). In addition, distress of the married due to inferitily or sexual disfucntion may lead to a decrease of the marital satisfaction (SamadaeeGelehkolaee et al, 2015).

This study found that more than half of the respondents experienced distress or difficulties in marital relationships (52.4\%), especially difficulty in communication with their

partners. Lack of communication between couples in this study may be due to a long-distance relationship. Other factors that may cause communication barriers in a couple relationship. In this study, it were found that many of the respondents were aged over 30 years old, had low education, and were unemployed. These conditions may affect their ability to maintain good communication or relationship with their partners.

Sexual dysfunction among women with gynecological problems can affect marital relationships. Previous studies reported that there was a significant relationship between sexual dysfunction and the quality of marital relationships in patients with cervical cancer and breast cancer, which both are types of gynecological problems (Fahami et al., 2017), as well as women with provoked vestibulodynia (Smith \& Pukall, 2011). Another study reported that sexual dysfunction has a higher risk to cause relationship conflict among young women with cancer gynecology (Guntupalli et al., 2017). Previous studies conducted in the UK reported that women with breast cancer had low satisfaction in married life (Hinnen et al., 2008).

The majority of respondents experienced sexual dysfunction $(90.2 \%)$. Sexual dysfunction in women is defined as a disorder that occurs in one or more of the entire normal sexual response cycles that affect sexual activity $(F$ et al., 2015). Previous study reported that women with cervical cancer experience a significant decrease in sexual activity (Fakunle \& Maree, 2019). Young women who suffer from ovarian or cervical cancer (one type of gynecological disease) have had chemotherapy, and married women have a very high risk of decreased sexual function (Guntupalli et al., 2017). In this study, not only women with gynecological cancers, but women with all types of gynecological problems such as myoma, endometriosis, cyst, and infertility experienced sexual dysfunction and it affected respondents' marital relationships ( $p$ value 0.002 ) with correlation coeffience 0.326 ; showing a moderate correlation. The majority of respondents (79.5\%) who experienced sexual dysfunction reported that they have marital relationship distress.

When one of the partners becomes ill, the regular interaction model shifts, which may reduce the couple's pleasure with one another (Chien et al., 2017). Another study, conducted in the United States on advanced cancer patients undergoing hormone therapy, found that individuals may be too preoccupied with disease care to recognize their spouses' marital satisfaction across in the phase of the illness (Zhou et al., 2011). There is conflicting research in regards to the potential impact of health problems on marital satisfaction. Some research found no relationship between cancer and chronic illness in cancer patients, while other studies found a link between poor general health and lower levels of marital satisfaction; greater symptoms are associated with lower levels of marital satisfaction (Korporaal et al., 2013).

Healthcare professionals need to provide counseling to help women with gynecological problems deal with their marital relationships. Additionally, psychoeducational intervention is apparently one method of preventing marital dissatisfaction. However, that intervention appears to reduce recurrence but does not appear to enhance marital dissatisfaction. Additionally, future research should be conducted to design and create effective interventions for healthcare providers to facilitate and improve pair marital satisfaction. 
Several studies have been found to explore the relationship between marital relationships and sexual dysfunction in women with gynecological problems, but most have focused on one or two types of gynecological problems.

\section{CONCLUSION AND RECOMMENDATION}

Almost all women with gynecological problems in this study experienced sexual dysfunction that affects marital relationships. Healthcare professionals need to pay more attention to facilitate women with gynecological problems to express their sexual activity and provide appropriate interventions to improve their sexual dysfunction. Future studies are needed to explore more deeply and use more sample sizes with longitudinal follow-up.

\section{REFERENCES}

Abbott-Anderson, K., \& Kwekkeboom, K. L. (2012). A systematic review of sexual concerns reported by gynecological cancer survivors. Gynecologic Oncology, 124(3), 477-489. https://doi.org/10.1016/j.ygyno.2011.11.030

Ashdown, B., Hackathorn, J., \& Clark, E. (2011). In and out of the bedroom: Sexual satisfaction in the marital relationship. Journal of Integrated Social Sciences, 2(1): 40-57.

Beaulah, P. (2018). Prevalence of gynaecological problems and their effect on working women. Indian Journal of Continuing Nursing Education, 19(1), 103-108.

Bryant, C. M., \& Wickrama, K. A. S. (2005). Marital relationships of African Americans: A contextual approach. In V. McLoyd, N. Hill, \& K. A. Dodge (Eds.), Emerging Issues in African American Family Life: Context, Adaptation, and Policy; 111-134. New York, NY: Guilford.

Brotto, L. A., Heiman, J. R., Goff, B., Greer, B., Lentz, G. M., Swisher, E., Tamimi, H., \& Van Blaricom, A. (2008). A psychoeducational intervention for sexual dysfunction in women with gynecologic cancer. Archives of Sexual Behavior, 37(2), 317-329. https://doi.org/10.1007/s10508-007-9196-x

Busby, D. M., Crane, D. R., Larson, J. H., \& Christensen, C. (1995). A revision of the Dyadic Adjustment Scale for use with distressed and nondistressed couples: Construct hierarchy and multidimensional scales. Journal of Marital and Family Therapy, 21(3), 289308. 0606.1995.tb00163.x

Chien, C. H., Chuang, C. K., Liu, K. L., Huang, X. Y., Pang, S. T., Wu, C. T., Chang, Y. H., \& Liu, H. E. (2017). Individual and mutual predictors of marital satisfaction among prostate cancer patients and their spouses. Journal of clinical nursing, 26(23-24), 4994-5003. https://doi.org/10.1111/jocn.13998

Damast, S., Alektiar, K. M., Goldfarb, S., Eaton, A., Patil, S., Mosenkis, J., ... Basch, E. (2012). Sexual functioning among endometrial cancer patients treated with adjuvant high-dose-rate intra-vaginal radiation therapy. International Journal of Radiation Oncology, Biology, Physics, 84(2), e187-e193. https://doi.org/10.1016/j.jrobp.2012.03.030

Dawson, M. L., Shah, N. M., Rinko, R. C., Veselis, C., \& Whitmore, K. E. (2017). The evaluation and management of female sexual dysfunction. The Journal of Family Practice, 66(12), 722-728.
Irchami, F. Y., Irfan, H., Isanawidya, H. P., Avie, A. B., Patmini, E., Nugroho, A., \& Rahman, M. N. (2015). Gangguan Hasrat Seksual Pada Wanita Pascasalin Dan Hubungannya Dengan Cara Persalinan (Sexual Desire Disorders in Postpartum Women and Its Relationship with the Way of Delivery). Jurnal Kesehatan Reproduksi, 2(1), 29-33. doi:10.22146/jkr.7117

Fahami, F., Mohamadirizi, S., \& Savabi, M. (2017). The relationship between sexual dysfunction and quality of marital relationship in genital and breast cancers women. Journal of Education and Health Promotion, 6(56), 1-6. https://doi.org/10.4103/jehp.jehp_186_14

Fakunle, I. E., \& Maree, J. E. (2019). Sexual function in South African women treated for cervical cancer. International Journal of Africa Nursing Sciences, 10, 124-130. https://doi.org/10.1016/j.ijans.2019.04.002

Guntupalli, S. R., Sheeder, J., Ioffe, Y., Tergas, A., Wright, J. D., Davidson, S. A., ... Flink, D. M. (2017). Sexual and marital dysfunction in women with gynecologic cancer. International Journal of Gynecological Cancer: Official Journal of the International Gynecological Cancer Society, 27(3), 603-607. https://doi.org/10.1097/IGC.0000000000000906

Handayani, Y. (2016). Komitmen, conflict resolution, dan kepuasan perkawinan pada istri yang menjalani hubungan pernikahan jarak jauh (commitment, conflict resolution, and marital satisfaction in wives who have long distance marriage relationships). Psikoborneo: Jurnal IImiah Psikologi, 4(3), 325-333.

Helms H.M. (2013) Marital Relationships in the Twenty-First Century. In: Peterson G., Bush K. (eds) Handbook of Marriage and the Family. Springer, Boston, MA. https://doi.org/10.1007/978-1-4614-3987-5_11

Hicks-Courant, K., Melamed, A., Worley, M. J. J., Kim, Y. B., Schorge, J. O., \& Rauh-Hain, J. A. (2018). Trends in place of death among patients with gynecologic cancer in the United States. Obstetrics and Gynecology, 131(6), 1111-1120. https://doi.org/10.1097/AOG.0000000000002614

Hinnen, C., Hagedoorn, M., Ranchor, A. V, \& Sanderman, R. (2008). Relationship satisfaction in women: a longitudinal case-control study about the role of breast cancer, personal assertiveness, and partners' relationship-focused coping. British Journal of Health Psychology, 13(Pt 4), 737-754. https://doi.org/10.1348/135910707X252431

Korporaal, M., Broese van Groenou, M. I., \& Tilburg, T. G. van. (2013). Health Problems and Marital Satisfaction Among Older Couples. Journal of Aging and Health, 25(8), 1279-1298. https://doi.org/10.1177/0898264313501387

Liavaag, A. H., Dørum, A., Bjøro, T., Oksefjell, H., Fosså, S. D., Tropé, C., \& Dahl, A. A. (2008). A controlled study of sexual activity and functioning in epithelial ovarian cancer survivors. A therapeutic approach. Gynecologic Oncology, 108(2), 348-354. https://doi.org/10.1016/j.ygyno.2007.10.009

Mok, S., Wong, K.-K., Lu, K., Munger, K., \& Nagymanyoki, Z. (2020). Molecular basis of gynecologic diseases (pp. 409-424). https://doi.org/10.1016/B978-0-12813257-9.00023-1 
Nappi, R. E., Cucinella, L., Martella, S., Rossi, M., Tiranini, L., \& Martini, E. (2016). Female sexual dysfunction (FSD): Prevalence and impact on quality of life (QoL). Maturitas, 94, 87-91. https://doi.org/10.1016/j.maturitas.2016.09.013

Nogueira, D. J., Minamisava, R., Teles, S. A., Souza, S., Cordeiro, J., Cirqueira, D. S., Brasil, V. V., Souza, A., Caetano, K., Oliveira, L., Lago, D., \& Barbosa, M. A. (2019). Factors associated with marital satisfaction and quality of life in family caregivers of patients with mental disorders. International Journal of Environmental Research and Public Health, 16(16), 2825. https://doi.org/10.3390/ijerph16162825

Nora, H., \& Khalishah, G. (2018). Gambaran jenis penyakit ginekologi di Rumah Sakit Umum Daerah dr. Zainoel Abidin Banda Aceh tahun 2017. Jurnal Kedokteran Nanggroe Medika, 1(4), 22-31.

Puechl, A. M., Chino, F., Havrilesky, L. J., Davidson, B. A., \& Chino, J. P. (2019). Place of death by region and urbanization among gynecologic cancer patients: 2006-2016. Gynecologic Oncology, 155(1), 98-104. https://doi.org/10.1016/j.ygyno.2019.07.013

Rosen, R., Brown, C., Heiman, J., Leiblum, S., Meston, C., Shabsigh, R., ... D'Agostino, R. J. (2000). The Female Sexual Function Index (FSFI): A multidimensional self-report instrument for the assessment of female sexual function. Journal of Sex \& Marital Therapy, 26, 191-208. https://doi.org/10.1080/009262300278597

Samadaee-Gelehkolaee, K., McCarthy, B. W., Khalilian, A., Hamzehgardeshi, Z., Peyvandi, S., Elyasi, F., \& Shahidi, M. (2015). Factors associated with marital satisfaction in infertile couple: A comprehensive literature review. Global Journal of Health Science, 8(5), 96-109. https://doi.org/10.5539/gjhs.v8n5p96

Schäfer, T., \& Schwarz, M. A. (2019). The Meaningfulness of Effect Sizes in Psychological Research: Differences Between Sub-Disciplines and the Impact of Potential Biases. Frontiers in Psychology, 10(813), 1-13 https://doi.org/10.3389/fpsyg.2019.00813
Shankar, A., Prasad, N., Roy, S., Chakraborty, A., Biswas, A. S., Patil, J., \& Rath, G. K. (2017). Sexual dysfunction in females after cancer treatment: An unresolved issue. Asian Pacific Journal of Cancer Prevention: APJCP, 18(5), 1177-1182. https://doi.org/10.22034/APJCP.2017.18.5.1177

Smith, K. B., \& Pukall, C. F. (2011). A systematic review of relationship adjustment and sexual satisfaction among women with provoked vestibulodynia. Journal of sex research, 48(2-3), 166-191. https://doi.org/10.1080/00224499.2011.555016

Sorokowski, P., Randall, A., Groyecka-Bernard, A., Frackowiak, T., Cantarero, K., Hilpert, P., ... Sorokowska, A. (2017). Marital satisfaction, sex, age, marriage duration, religion, number of children, economic status, education, and collectivistic values: Data from 33 countries. Frontiers in Psychology, 8, 1-7. https://doi.org/10.3389/fpsyg.2017.01199

Vermeer, W. M., Bakker, R. M., Kenter, G. G., Stiggelbout, A. M., \& Ter Kuile, M. M. (2016). Cervical cancer survivors' and partners' experiences with sexual dysfunction and psychosexual support. Support Care Cancer, 24(4), 1679-1687. https://doi.org/10.1007/s00520-015-2925-0

Yuan, R., Zhang, C., Li, Q., Ji, M., \& He, N. (2021). The impact of marital status on stage at diagnosis and survival of female patients with breast and gynecologic cancers: A meta-analysis. Gynecologic Oncology.

https://doi.org/10.1016/j.ygyno.2021.06.008

Zegeye, B., Woldeamanuel, G. G., Negash, W., \& Shibre, G. (2020). Sexual satisfaction and its associated factors among married women in Northern Ethiopia. Ethiopian Journal of Health Sciences, 30(2), 169178. https://doi.org/10.4314/ejhs.v30i2.4

Zhou, E. S., Kim, Y., Rasheed, M., Benedict, C., Bustillo, N. E., Soloway, M.,...Penedo, F. J. (2011). Marital satisfaction of advanced prostate cancer survivors and their spousal caregivers: The dyadic effects of physical and mental health. Psycho-Oncology, 20(12), 1353-1357. https://doi.org/10.1002/pon.1855 